This document is confidential and is proprietary to the American Chemical Society and its authors. Do not copy or disclose without written permission. If you have received this item in error, notify the sender and delete all copies.

\title{
Metal Oxide Aerogels with Controlled Crystallinity and Faceting from the Epoxide-Driven Cross-Linking of Colloidal Nanocrystals
}

\begin{tabular}{|r|l|}
\hline Journal: & ACS Applied Materials \& Interfaces \\
\hline Manuscript ID & am-2018-03754v.R1 \\
\hline Manuscript Type: & Article \\
\hline Date Submitted by the Author: & 18 -Apr-2018 \\
\hline Complete List of Authors: & $\begin{array}{l}\text { Berestok, Taisiia; Institut de Recerca en Energia de Catalunya, } \\
\text { Guardia, Pablo; Institut de Recerca en Energia de Catalunya, } \\
\text { Du, Ruifeng; Institut de Recerca en Energia de Catalunya } \\
\text { Blanco Portals, Javier; Universitat de Barcelona Facultad de Fisica, } \\
\text { Enginyeries: Electrònica } \\
\text { Colombo, Massimo; Istituto Italiano di Tecnologia, Nanochemistry } \\
\text { Estrade, Sonia; Universitat de Barcelona, Electronics } \\
\text { Peiró, Francesca; Universitat de Barcelona, EME/XaRMAE/IN2UB, Dept. } \\
\text { d'Electrònica } \\
\text { Brock, Stephanie; Wayne State University, Department of Chemistry; } \\
\text { Wayne State University, Department of Chemistry } \\
\text { Cabot, Andreu; Catalonia Institute for Energy Research, Dept Electrònica }\end{array}$ \\
\hline
\end{tabular}




\title{
Metal Oxide Aerogels with Controlled Crystallinity
}

\section{and Faceting from the Epoxide-Driven Cross-}

\section{Linking of Colloidal Nanocrystals}

Taisiia Berestok, ${ }^{\dagger,}$ Pablo Guardia,${ }^{\dagger}$ Ruifeng Du,,${ }^{\dagger}$ Javier Blanco Portals,,${ }^{\ddagger}$, Massimo Colombo, ${ }^{\perp}$

Sònia Estradé,,${ }^{\ddagger}{ }^{\perp}$ Francesca Peiró,,${ }^{\ddagger}{ }^{\perp}$ Stephanie L. Brock, ${ }^{\S}$ and Andreu Cabot, $,^{\dagger,}, *$

† Catalonia Institute for Energy Research - IREC, 08930 Sant Adrià de Besòs, Barcelona, Spain

¥ LENS-MIND, Departament d’Enginyeria Electrònica I Biomèdica, Universitat de Barcelona, 08028, Barcelona, Spain

${ }^{\perp}$ Institute of Nanoscience and Nanotechnology (In2UB), Universitat de Barcelona, 08028, Barcelona, Spain

'Nanochemistry Department, Istituto Italiano di Tecnologia, via Morego 30, 16130 Genova, Italy

$\S$ Department of Chemistry, Wayne State University, Detroit, Michigan 48202, United States

' ICREA, Pg. Lluís Companys 23, 08010 Barcelona, Spain

KEYWORDS. Aerogel, ceria, nanocrystal, sol-gel, ligand exchange.

\begin{abstract}
We present a novel method to produce crystalline oxide aerogels which is based on the cross linking of preformed colloidal nanocrystals (NCs) triggered by propylene oxide (PO). Ceria and titania were used to illustrate this new approach. Ceria and titania colloidal NCs with tuned geometry and crystal facets were produced in solution from the decomposition of a suitable
\end{abstract}


salt in the presence of oleylamine (OAm). The native surface ligands were replaced by amino acids, rendering the NCs colloidally stable in polar solvents. The NC colloidal solution was then gelled by adding PO, which gradually stripped the ligands from the NC surface, triggering a slow NC aggregation. NC-based metal oxide aerogels displayed both high surface areas and excellent crystallinity associated with the crystalline nature of the constituent building blocks, even without any annealing step. Such NC-based metal oxide aerogels showed higher thermal stability compared with aerogels directly produced from ionic precursors using conventional sol-gel chemistry strategies.

\section{INTRODUCTION}

Mesoporous materials with high surface to bulk ratios are essential components in applications involving interaction with the surrounding media, including catalysis, sensing, filtering and adsorption. ${ }^{1-2}$ Among them, the highly porous disordered networks found in gels and aerogels are particularly appealing owing to the high accessibility they provide to fluids and reactants.

Such highly porous materials are commonly produced from ionic or molecular precursors following sol-gel chemistry approaches. Common protocols involve the use of metal alkoxide precursors that undergo hydrolysis and condensation. ${ }^{3-4}$ Alternative metal salts are also used with the aid of an epoxide as gelation promoter. ${ }^{5-8}$ Due to the moderate temperature of the gelation processes, the gels produced in this way are characterized by low crystallinities, thus generally requiring thermal annealing to achieve long range atomic order. This thermal process usually results in a reduction of the surface area and prevents accurate control over crystallographic domain size, facets and phase.

An alternative strategy to produce mesoporous materials with full versatility in terms of crystal domain parameters and composition is the cross-linking of pre-synthesized colloidal NCs. ${ }^{9-12}$ This 
approach allows exploiting the huge palette of colloidal NCs with precisely controlled properties currently available. It thus offers evident advantages in terms of producing porous nanomaterials with improved crystallinity, controlled composition and structure and tuned surface facets, and porous nanocomposites with complex composition and phase distributions.

Colloidal NCs are generally produced using long chain surface organic ligands that control their growth and sterically stabilize them in non-polar solvents. ${ }^{13-14}$ To optimize the NCs' performance, such ligands are generally replaced by smaller molecules that maximize or tune interaction with the surrounding media. In this vein, the use of short amino acids as surface ligands provides NCs with a high versatility and thus an ample range of potential applications, from biomedical, taking advantage of the biocompatibility of amino acids, ${ }^{15}$ to technological, taking advantage for instance of the efficient $\mathrm{CO}_{2}$ adsorption provided by the amino group. ${ }^{16-19}$ Additionally, the presence of both a carboxyl and an amino group provides amino acids with a very appealing surface chemistry versatility, since depending on $\mathrm{pH}$, the terminal amino or carboxyl group can bind to the surface. ${ }^{20-}$ ${ }^{22}$ Thus, the surface can be charged positively or negatively, which controls the capability of the $\mathrm{NC}$ to interact with different species in the media.

Among metal oxides, ceria is a particularly appealing material, especially in the form of a highly porous gel/aerogel. Cerium presents relatively stable $\mathrm{Ce}^{3+}$ and a $\mathrm{Ce}^{4+}$ oxidation states which can be exploited for redox chemistry. ${ }^{23}$ This particularity and its high photo, thermal, and chemical stability makes ceria an excellent candidate material for a number of application fields that involve interaction with the surrounding media, e.g. heterogeneous catalysis, ${ }^{24-28}$ solid oxide fuel cells, ${ }^{29}$ gas sensors ${ }^{30}$ and environmental remediation. ${ }^{31}$ While having no biological role, its low toxicity and its particular characteristics also makes ceria an interesting material for biomedical 
applications, e.g. as scavenger of reactive oxidation species through shuttling between $\mathrm{Ce}^{3+}$ and $\mathrm{Ce}^{4+}$ oxidation states. ${ }^{32}$

Titanium dioxide is one of the most used metal oxides in the field of heterogeneous catalysis, and particularly in photocatalysis. Its advantages include the high abundance of its constituent elements, a low toxicity, being used in paints, sunscreen and even food coloring, an outstanding stability, a direct bandgap, a low density of recombination centers, a sufficiently positive valence band edge to oxidize water to oxygen, and overall a very suitable surface for a range of applications involving interaction with the media. ${ }^{33,34}$

Recent advances in the synthesis of colloidal ceria and titania NCs with tuned size and shape make such building blocks particularly appropriate to produce NC-based mesoporous nanomaterials. ${ }^{35,36}$ Here we use preformed ceria and titania NCs functionalized with amino acids to exemplify a novel strategy to produce metal oxide gels and aerogels. The process is based on the ligand displacement from the NCs surface by the introduction of an epoxide, which triggers the cross-linking of NCs into a porous network.

\section{EXPERIMENTAL SECTION}

Materials. Cerium(III) nitrate hexahydrate $\left(\mathrm{Ce}\left(\mathrm{NO}_{3}\right)_{3} \cdot 6 \mathrm{H}_{2} \mathrm{O}, 99 \%\right)$, 1-octadecene (ODE, $\mathrm{C}_{18} \mathrm{H}_{36}, 90 \%$ ), oleylamine (OAm, $\mathrm{C}_{18} \mathrm{H}_{37} \mathrm{~N}, 70 \%$ ), L-glutamine (Gln, $\mathrm{C}_{5} \mathrm{H}_{10} \mathrm{~N}_{2} \mathrm{O}_{3}$, $\geq 99 \%$ ), trifluoroacetic acid (TFA, $\mathrm{C}_{2} \mathrm{HF}_{3} \mathrm{O}_{2}, 99 \%$ ), N-methylformamide (MFA, $\mathrm{C}_{3} \mathrm{H}_{7} \mathrm{NO}, 99.8 \%$ ), propylene oxide ( $\mathrm{PO}, \mathrm{C}_{3} \mathrm{H}_{6} \mathrm{O}, \geq 99.5 \%$ ), neopentyl glycol diglycidyl ether $\left(\mathrm{NGDE}, \mathrm{C}_{11} \mathrm{H}_{20} \mathrm{O}_{4}\right.$, $\geq 95 \%$ ), dopamine hydrochloride (DA, $\mathrm{C}_{8} \mathrm{H}_{12} \mathrm{ClNO}_{2}, 98 \%$ ), glutamic acid (Glu, $\mathrm{C}_{5} \mathrm{H}_{9} \mathrm{NO}_{4}, \geq 99 \%$ ), titanium(IV) fluoride $\left(\mathrm{TiF}_{4}, 99 \%\right)$, and tetramethylammonium hydroxide pentahydrate (TMAOH, 
$\mathrm{C}_{4} \mathrm{H}_{23} \mathrm{NO}_{6}, \geq 99 \%$ ) were purchased from Sigma-Aldrich. Hexane, 2-propanol, acetone and methanol were of analytical grade and were purchased from Panreac. OAm was purified by vacuum distillation. All other reagents were used as received without further purification. All NC syntheses were carried out in three-neck round-bottom flasks equipped with a condenser connected to a standard Schlenk line. Air and moisture-sensitive chemicals were handled and stored under inert atmosphere.

Synthesis of ceria spherical NCs: Ceria NCs were synthesized though the thermal decomposition of cerium(III) nitrate within ODE in the presence of OAm, according to a procedure we previously reported. ${ }^{35}$ Briefly, $0.434 \mathrm{~g}(1 \mathrm{mmol})$ of cerium(III) nitrate hexahydrate were mixed with $2 \mathrm{~mL}(6 \mathrm{mmol})$ of OAm in $4 \mathrm{~mL}$ of ODE in a $25 \mathrm{~mL}$ three neck flask and under magnetic stirring. After degassing the mixture for 30 minutes at $80^{\circ} \mathrm{C}$, the obtained brown colour solution was heated under argon flow up to $300^{\circ} \mathrm{C}$ at a rate of $15^{\circ} \mathrm{C} / \mathrm{min}$. The mixture was allowed to react at this temperature for 60 minutes before cooling it down. NCs were washed with acetone at least four times and finally dispersed in a suitable solvent (hexane, chloroform or toluene) with a concentration of $10 \mathrm{mg} / \mathrm{mL}$ for later use. Such NCs were labelled as ceria OAm-NCs.

Synthesis of titania nanoplates: Titanium dioxide NCs with plate morphology were synthesized via seeded growth following the procedure reported by Gordon et al.. ${ }^{36}$ The synthesis started from the preparation of a $0.2 \mathrm{M}$ Ti precursor stock solution by dissolving the proper amount of $\mathrm{TiF}_{4}$ within a $1 \mathrm{M} \mathrm{OAc}$ solution in ODE. This solution was maintained at $80{ }^{\circ} \mathrm{C}$ for $30 \mathrm{~min}$ under stirring within an Ar-filled glovebox. Meanwhile, $30 \mathrm{mmol}$ of OAm, $1.5 \mathrm{mmol}$ of OAc and $10 \mathrm{~mL}$ of ODE were loaded into a $100 \mathrm{~mL}$ flask and degassed under vacuum and magnetic stirring at $120^{\circ} \mathrm{C}$ for $60 \mathrm{~min}$. After degassing, the flask was cooled down to $60^{\circ} \mathrm{C}$, and $1.5 \mathrm{~mL}$ of the $\mathrm{TiF}_{4}$ stock solution was injected. Then, temperature was increased up to $290{ }^{\circ} \mathrm{C}$ and maintained at this 
point for $10 \mathrm{~min}$ to allow seed formation. Subsequently, $8 \mathrm{~mL}$ of the $\mathrm{TiF}_{4}$ stock solution were continuously added into the flask at a rate of $0.3 \mathrm{~mL} / \mathrm{min}$ using a syringe pump. Afterward, the reaction was stopped by removing the heating mantle. Finally, NCs were isolated by adding a mixture of 2-propanol and methanol and followed by centrifuging at $6000 \mathrm{rpm}$. These NCs were labelled as $\mathrm{TiO}_{2} \mathrm{OAm}-\mathrm{NCs}$.

Surface modification with amino acids: The procedure used to replace native organic ligands with amino acids was inspired by previous work by J. de Roo et al. ${ }^{19}$ Ligand exchange processes were carried out in air atmosphere. In a typical procedure, $1 \mathrm{~mL}$ of NCs dispersed in hexane (typically, $10 \mathrm{mg} / \mathrm{mL}$ ) was added to a solution (prepared using mild sonication) of $7 \mathrm{mg}$ of Gln in $1 \mathrm{~mL}$ MFA, followed by the addition of TFA $(0.2 \mathrm{mM})$. The two phase mixture obtained was stirred until NCs were transferred from the upper to the bottom phase. Then, the hexane phase was discarded and a hexane/acetone mixture was added to the remaining MFA solution containing the NCs. Then NCs were precipitated and subsequently washed at least two more times by addition of MFA as a solvent and a mixture of hexane/acetone and acetonitrile as an antisolvent. Finally, NCs were redispersed in a polar solvent such as water, methanol or MFA for later use. NCs obtained after surface modification with Gln were labelled as Gln-NCs.

Preparation of NC-based gels: The gelation procedure was carried out in air. In a typical experiment, $2 \mathrm{~mL}$ of MQ-water were added to $2 \mathrm{~mL}$ of a MFA solution of amino acid functionalized NCs $(20 \mathrm{mg} / \mathrm{mL})$. The mixture was sonicated for approximately $15 \mathrm{~min}$. Then gelation was induced by adding $4 \mathrm{~mL}$ of PO and leaving the solution undisturbed. Gelation started after $1 \mathrm{~h}$ of storing undisturbed the solution and it was completed within $24 \mathrm{~h}$ but gels were aged for several days. Then, MFA was carefully replaced by acetone using $5 \mathrm{~mL}$ of acetone each time. It must be noted that the solvent exchange should be conducted with special care to avoid 
destroying the NC network structure. The solvent exchange was repeated at least 6 times to ensure complete removal of MFA.

Preparation of ceria gel from a cerium salt: Gelation of a cerium chloride sol was performed under ambient conditions following a previously reported procedure. ${ }^{8}$ Briefly, 1 mmol of $\mathrm{CeCl}_{3} \cdot 6 \mathrm{H}_{2} \mathrm{O}$ was dissolved in $3 \mathrm{~mL}$ of methanol. To the obtained mixture, $10 \mathrm{~mL}$ of PO was added. The formed solution was shaken vigorously for approximately 10 seconds and left undisturbed. The gelation occurred in $30 \mathrm{~min}$ and was followed by changing the sol color from transparent to milky white and light brown when the gel was formed. The obtained gel was aged undisturbed for $12 \mathrm{~h}$. Afterward the solvent was exchanged by fresh acetone and isopropanol in order to get rid of unreacted products.

Gel drying into aerogel: In order to prevent collapsing its porous structure, gels were dried from supercritical $\mathrm{CO}_{2}$. Briefly, the gel in acetone was loaded into a super-critical point dryer (SCD) chamber. Then, the chamber was sealed and it was slowly filled with liquid $\mathrm{CO}_{2}$ until the pressure reached 73 bar. To ensure that the $\mathrm{CO}_{2}$ was in liquid state, the temperature of the system was maintained at $17-18^{\circ} \mathrm{C}$ using a Peltier element. After overnight storage undisturbed, the liquid $\mathrm{CO}_{2}$ inside of the chamber was half-drained and fresh $\mathrm{CO}_{2}$ was introduced. This procedure was repeated at least 6 times in one-hour intervals in order to fully replace acetone with liquid $\mathrm{CO}_{2}$. Then, the Peltier element was switched off and the chamber was heated up to $39{ }^{\circ} \mathrm{C}$ resulting in a pressure increase up to 80-90 bars and the transition of the $\mathrm{CO}_{2}$ from liquid to a supercritical phase. The sample was kept under these conditions for $1 \mathrm{~h}$ followed by slowly releasing the pressure while keeping the temperature constant.

Structural and chemical characterization: Transmission electron microscopy (TEM) characterization was carried out using a ZEISS LIBRA 120, operating at $120 \mathrm{kV}$. High resolution 
TEM (HRTEM) analyses were performed in a JEOL 2010F TEM operating at an accelerating voltage of $200 \mathrm{kV}$. Samples were prepared by drop casting a diluted solution of NCs onto a carbon coated copper grid (200 mesh). Images were analyzed with the Gatan Digital Micrograph software. X-ray power diffraction (XRD) analyses were carried out on a Bruker AXS D8 ADVANCE X-ray diffractometer with $\mathrm{Ni}$-filtered ( $2 \mu \mathrm{m}$ thickness $) \mathrm{Cu} \mathrm{K} \alpha 1$ radiation $(\lambda=1.5406 \AA)$. Samples were drop casted (200-500 $\mu \mathrm{L}$ at a concentration of about $3 \mathrm{mg} / \mathrm{mL})$ onto a zero-background silicon wafer. UV-vis absorption spectra were recorded on a PerkinElmer LAMBDA 950 UV-vis spectrophotometer. Samples were prepared by diluting $100 \mu \mathrm{L}$ in $3 \mathrm{~mL}$ of chloroform inside a 10 $\mathrm{mm}$ path length quartz cuvette. FTIR spectroscopy investigations were carried out using a PerkinElmer FT-IR 2000 spectrophotometer. Spectra were recorded from $500 \mathrm{~cm}^{-1}$ to $4000 \mathrm{~cm}^{-1}$. Thermogravimetric analyses (TGA) were carried out on a PerkinElmer Diamond TG/DTA instrument. For TGA analysis, samples were thoroughly dried and $20 \mathrm{mg}$ of the dried powder was loaded into a ceramic pan. Measurements were carried out in an air atmosphere from ambient temperature to $700{ }^{\circ} \mathrm{C}$ at a heating rate of $5{ }^{\circ} \mathrm{C} / \mathrm{min}$. Dynamic light scattering (DLS) measurements were performed using a Zeta Sizer (Malvern Instruments) equipped with a $4.0 \mathrm{~mW} \mathrm{HeNe}$ laser operating at $633 \mathrm{~nm}$ and an avalanche photodiode detector. The specific surface area and pore size of the materials was determined by $\mathrm{N}_{2}$ adsorption at $77 \mathrm{~K}$ using a Tristar II 3020 Micromeritics system. Specific areas were calculated using the Brunauer-Emmet-Teller (BET) method, from the analysis of the adsorption at $\mathrm{P} / \mathrm{P}_{0}=0.999$. Specific surface areas and pore size distributions were obtained from the materials annealed at $400{ }^{\circ} \mathrm{C}$ for $2 \mathrm{~h}$ under air atmosphere using a heating ramp of $2{ }^{\circ} \mathrm{C} / \mathrm{min}$.

RESULTS AND DISCUSSION 
Quasi-spherical ceria NCs with an average size of $7 \pm 1 \mathrm{~nm}$ were produced following our previously reported procedure. ${ }^{35}$ In brief, NCs were obtained through the decomposition at $300{ }^{\circ} \mathrm{C}$ of cerium nitrate hexahydrate in an ODE solution containing OAm (Figure 1a). The presence of OAm at the surface of the ceria NCs limited their growth and rendered them soluble in non-polar organic solvents.

OAm was replaced by amino acids using a two-phase procedure involving the mixing of the selected amino acid dissolved in MFA and TFA with a hexane solution containing the NCs. This mixture was mixed and sonicated for several minutes, resulting in the transfer of the NCs from hexane to MFA (see experimental section for details). The final NCs could be redispersed in polar solvents such as MFA, isopropanol, methanol or water. Figure 1 displays TEM micrographs of ceria NCs before (OAm-NCs) and after ligand exchange with Gln (Gln-NCs). Similar hydrodynamic radii were measured by DLS from OAm-NCs dispersed in hexane and Gln-NCs in different polar solvents (Figure $1 \mathrm{e})$. Additionally, positive zeta potentials $(+26 \mathrm{mV})$ were measured for Gln-NCs, which was consistent with the passivation of these NCs with a ligand containing protonated amino group (Figure $1 \mathrm{f}$ ). 


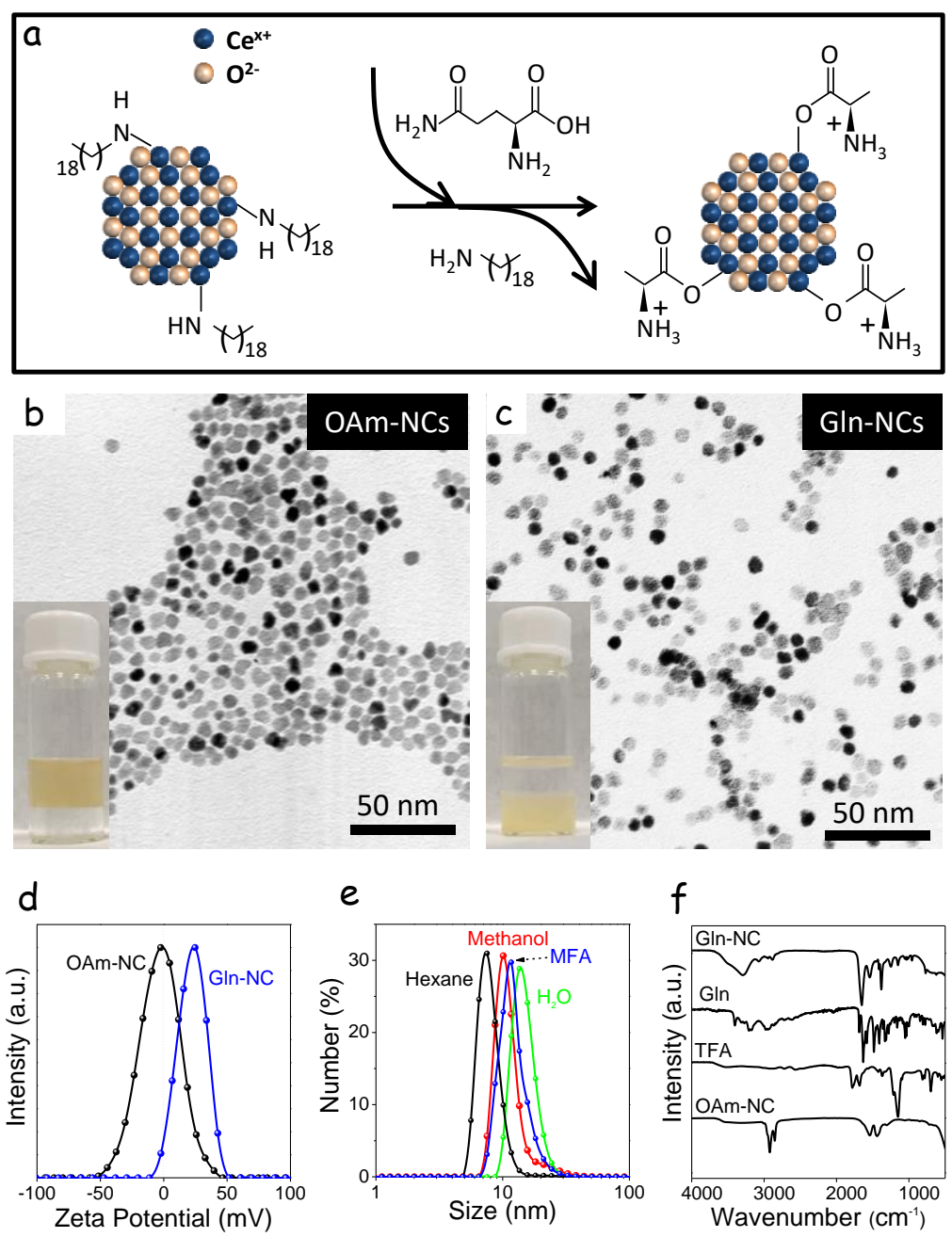

Figure 1. a) Scheme of the OAm-to-Gln ligand exchange procedure. b) TEM micrograph of ceria NCs with native organic ligands (OAm-NC). Inset shows a photograph of the two-phase mixture used for ligand exchange purposes before mixing. The top phase corresponds to the nonpolar solvent (hexane) containing the NCs, and the bottom phase to the polar solvent (MFA) containing the amino acid and TFA. c) TEM micrograph of ceria NCs after ligand exchange with Gln (GlnNC). Inset shows the two-phase mixture after ligand exchange, with the NCs in the polar phase. d) Zeta potential measurement of OAm-NCs and Gln-NCs. e) DLS curves of OAm-NCs in hexane and Gln-NC in $\mathrm{H}_{2} \mathrm{O}$, methanol and MFA.f) FTIR spectra of OAm-NCs, TFA, Gln and Gln-NCs. 
FTIR analysis confirmed the displacement of OAm from the NCs surface upon ligand exchange with Gln (Figure $1 \mathrm{f}$ ). The FTIR spectrum of the NCs after ligand exchange showed a strong suppression of the organic ligand fingerprint, i.e. the peaks in the region of $2820-2946 \mathrm{~cm}^{-1}$ attributed to the $\mathrm{C}-\mathrm{H}$ stretching vibration. Besides, the similarity of the Gln and Gln-NC FTIR spectra, and in particular the peaks at around $1538 \mathrm{~cm}^{-1}$ and $1650 \mathrm{~cm}^{-1}$ ascribed to $\mathrm{N}-\mathrm{C}=\mathrm{O}$ and $\mathrm{NH}_{2}$ stretching from the Gln molecule, confirmed the presence of this amino acid on the surface of ceria NCs after the ligand exchange process.

Amino acid-functionalized NCs were highly stable in solution, but they could be destabilized through addition of a base. We triggered the gelation of MFA solutions of ceria NCs by addition of PO. Gelation became visually evident $4 \mathrm{~h}$ after the addition of the epoxide and it evolved for the following 20 h. $24 \mathrm{~h}$ after the addition of PO, the solvent was exchanged several times to eliminate residual reaction products and it was finally replaced by acetone. Then the gel was loaded into a SCD chamber where acetone was replaced by liquid $\mathrm{CO}_{2}$. Finally, the gel was dried from supercritical $\mathrm{CO}_{2}$ to obtain a self-standing monolithic aerogel (see details in the experimental section, Figures 2 and S1). Upon the supercritical drying process, the gel lost ca. $20 \%$ of its volume (Figures 2d, S1).

TEM and SEM micrographs (Figures $2 \mathrm{a}$ and $2 \mathrm{~b}$, respectively) displayed the ceria aerogels to have highly porous structures made of randomly interconnected ceria NCs. HRTEM analysis revealed that most ceria NCs were interconnected with no crystallographic alignment (Figure 2e).

Figure 2c shows adsorption-desorption isotherm obtained from a NC-based ceria aerogel annealed at $400{ }^{\circ} \mathrm{C}$ for $2 \mathrm{~h}$. A specific surface area of $200 \pm 20 \mathrm{~m}^{2} / \mathrm{g}$ was calculated using the Brunauer-Emmett-Teller (BET). This value was over 3-fold larger than the measured from the same ceria NCs directly precipitated in the form of a nanopowder through the use of an antisolvent 
and centrifugation, $63 \mathrm{~m}^{2} / \mathrm{g} \cdot{ }^{35} \mathrm{NC}$-based ceria aerogels displayed a type IV adsorption-desorption isotherm with a hysteresis associated with capillary condensation (Figure 2c). Barrett-JoynesHalenda $(\mathrm{BJH})$ plots of the pore-size distribution of the aerogel sample revealed broad pore size distributions, consistent with the porous but random nature of the aerogel (Figure S2).
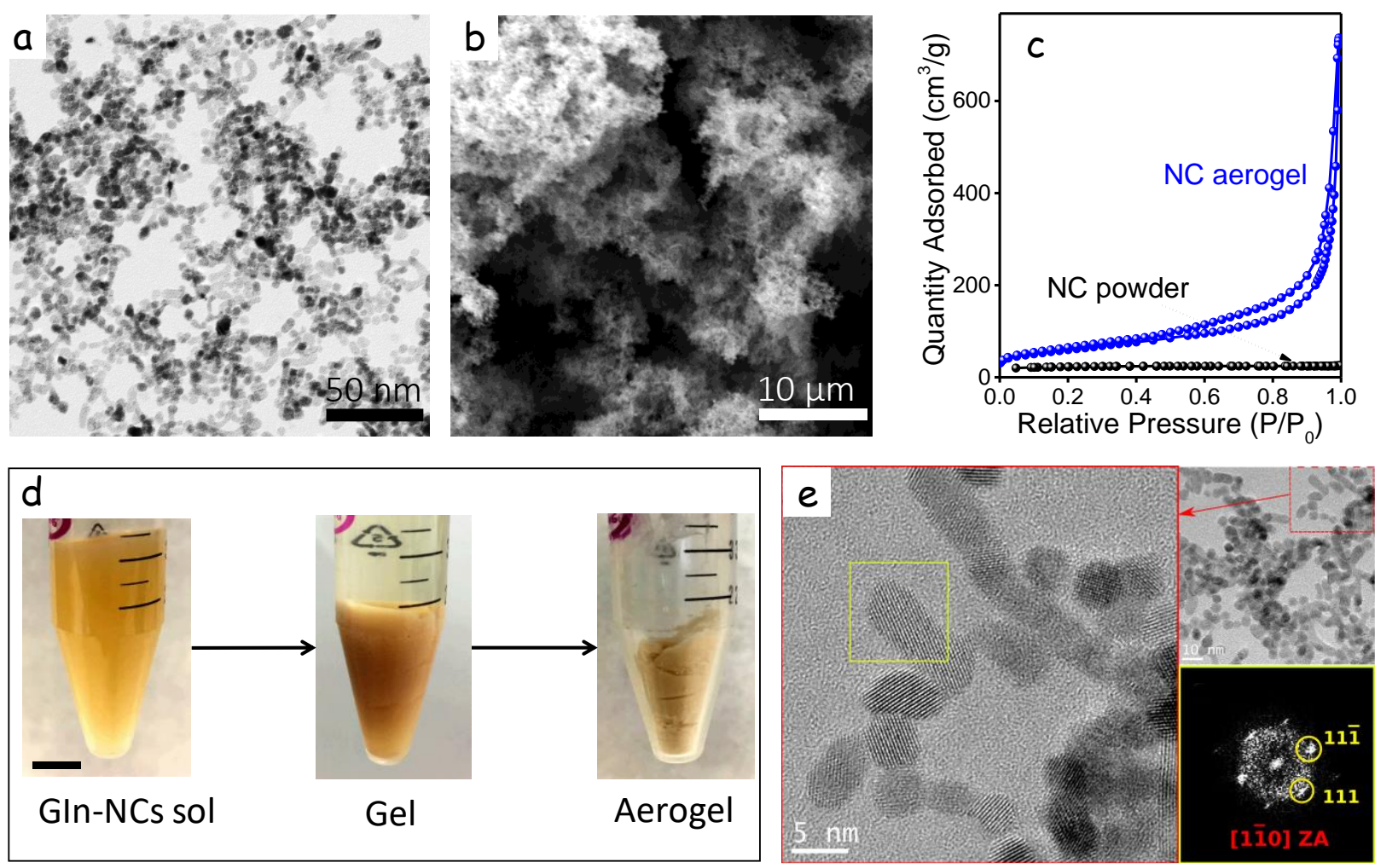

Figure 2. a) TEM micrograph of the NC-based ceria gel obtained by the cross-linking of ceria NCs triggered by the addition of PO. b) SEM micrograph of the NC-based ceria aerogel obtained from drying the gel from supercritical $\mathrm{CO}_{2}$. c) Adsorption-desorption isotherm obtained from a NC-based ceria aerogel and from a NC powder obtained by precipitation of the colloidal NCs using an antisolvent and posterior centrifugation. Both materials were annealed at $400{ }^{\circ} \mathrm{C}$ for $2 \mathrm{~h}$. d) Optical photographs of the colloidal ceria NCs, the gel and the aerogel. e) HRTEM micrograph 
of a NC-based $\mathrm{CeO}_{2}$ aerogel including a zoomed micrograph of the highlighted area in red and the FFT of the highlighted area in yellow.

XRD analysis demonstrated that, unlike aerogels conventionally produced from sol-gel chemistry methods, as-prepared NC-based aerogels were highly crystalline, retaining the crystallinity of the precursor NCs (Figure 3). XRD patterns displayed the reflections of the $\mathrm{CeO}_{2}$ fluorite structure (space group $=$ Fm3m, JCPDS card No 34-0394) with lattice parameter $a=$ $0.5412 \mathrm{~nm}$.

To further compare the two methodologies, we produced ceria aerogels from the gelation of a ceria chloride solution, also using PO as gelator promoter, as described by C. Laberty-Robert et al. ${ }^{8}$ Figure 3a displays optical photographs and SEM micrographs of the aerogel produced by this strategy before and after annealing at $400{ }^{\circ} \mathrm{C}$. Using this approach, the BET specific surface areas of the as-produced aerogel were larger, up to $380 \mathrm{~m}^{2} / \mathrm{g}$, than that of the NC-based aerogel. However, this initial ceria aerogel was mostly amorphous and a thermal treatment at $400{ }^{\circ} \mathrm{C}$ was required to crystallize it (Figure 3c). During this thermal annealing process, notable shrinkage of the aerogel took place and the monolithic structure was lost (Figure 3a). Additionally, the specific surface area obtained decreased down to $180 \mathrm{~m}^{2} / \mathrm{g}$, below that obtained from the initial NC-based aerogel already displaying a proper crystallinity (Figure 3b). Additionally, NC-based aerogels did not collapse during the thermal treatment at $400{ }^{\circ} \mathrm{C}$ and their structure was mostly maintained. 

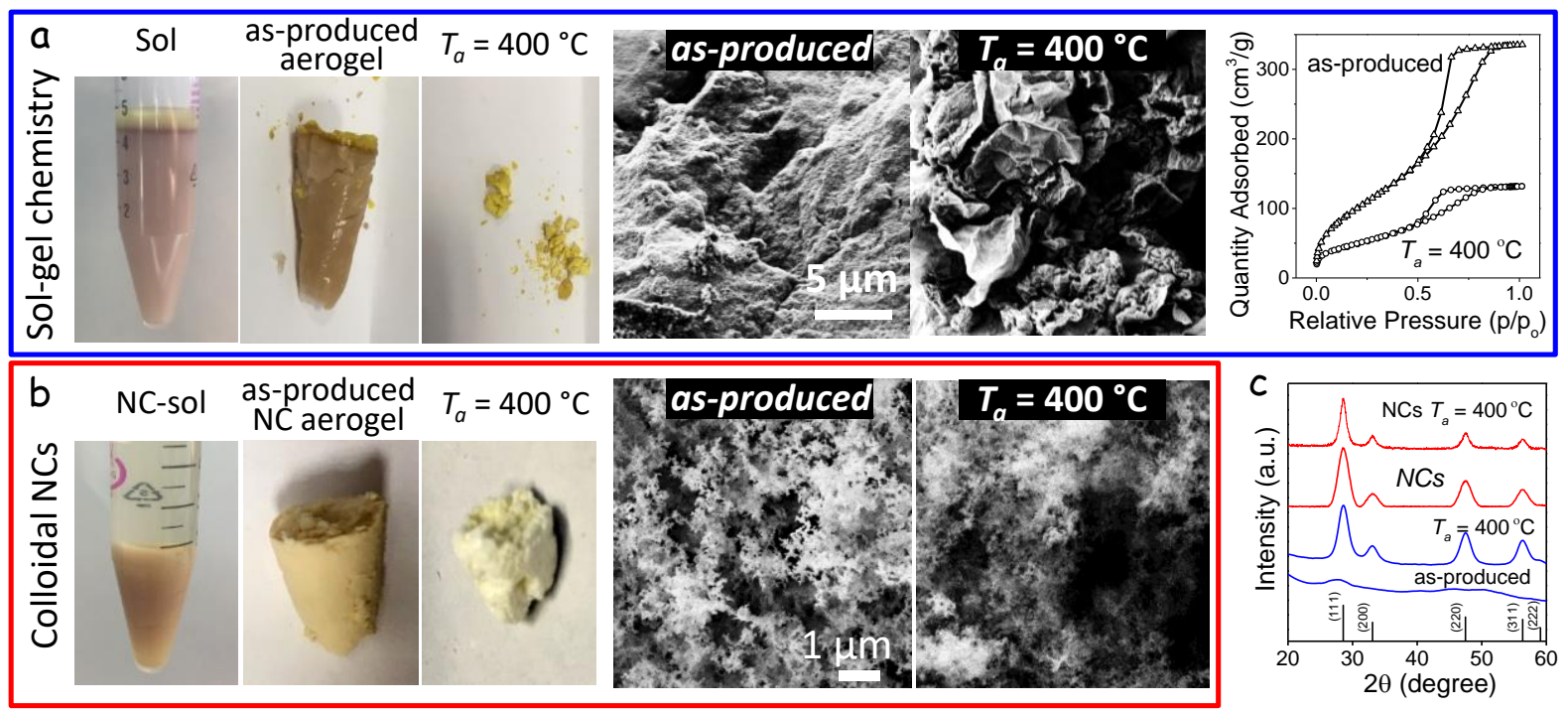

Figure 3. a) Gel and aerogel produced following a sol-gel chemistry approach: ${ }^{8}$ Optical photographs of the sol, the as-produced aerogel and the aerogel annealed at $400{ }^{\circ} \mathrm{C}$; SEM micrographs of the as-produced aerogel and the aerogel annealed at $400{ }^{\circ} \mathrm{C}$; and adsorptiondesorption isotherms of the as-produced aerogel and the aerogel annealed at $400{ }^{\circ} \mathrm{C}$. b) Gel and aerogel produced from the cross-linking of colloidal NCs: Optical photographs of the sol, the asproduced aerogel and the aerogel annealed at $400{ }^{\circ} \mathrm{C}$; and SEM micrographs of the as-produced aerogel and the aerogel annealed at $400{ }^{\circ} \mathrm{C}$. c) XRD patterns of (from bottom to top) the ceria aerogel produced following a sol-gel chemistry approach, as-produced and after annealing at 400 ${ }^{\circ} \mathrm{C}$; the ceria NCs and the ceria NC-based aerogel annealed at $400{ }^{\circ} \mathrm{C}$.

Introducing PO into a Gln-NC sol resulted in a slow cross-linking of the NCs into a disordered network, i.e. a gel. We hypothesize the NC cross-linking was triggered by a gradual stripping of Gln from the NC surface through interaction with PO. PO interacted with the acid group bond at the cerium sites, resulting in an opening of the PO ring and the stripping of the amino acid. ${ }^{37} \mathrm{~A}$ scheme of the proposed gelation mechanism is shown in Figure 4. 
FTIR spectra of the gel supernatant showed the presence of peaks at around $1538 \mathrm{~cm}^{-1}$ and 1650 $\mathrm{cm}^{-1}$ ascribed to $\mathrm{N}-\mathrm{C}=\mathrm{O}$ and $\mathrm{NH}_{2}$ stretching, confirming stripping of Gln during the gelation process. FTIR spectra of the aerogel also displayed that part of the Gln remained on the NC surface as required to prevent the full collapse of the structure in solution. Additionally, TGA analysis confirmed the amount of organic in the final aerogel to be ca. $25 \%$ lower than in the precursor Gln-NCs, confirming a partial ligand removal.
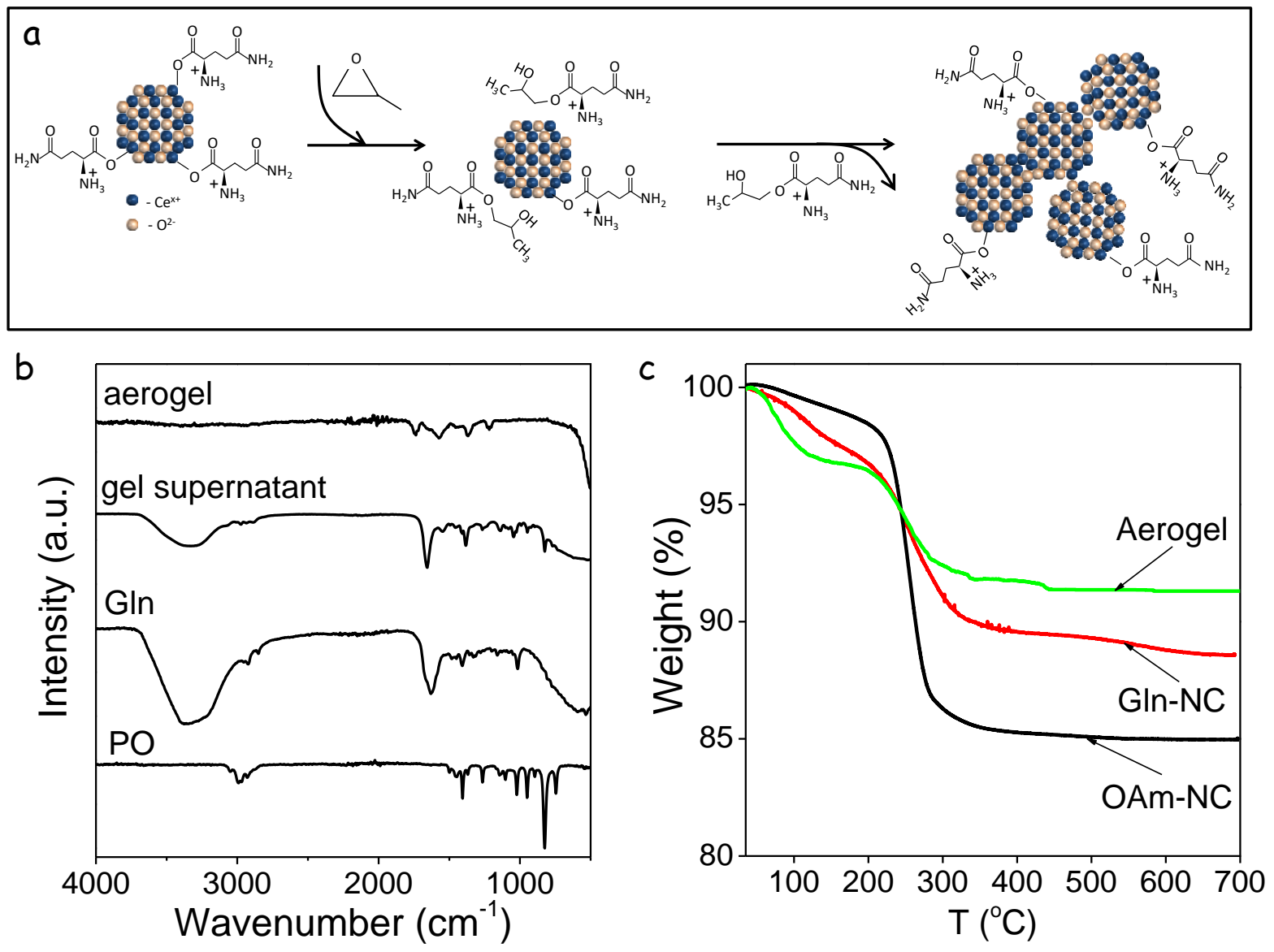

Figure 4. a) Schematic representation of the gelation of the Gln-NC solution triggered by the introduction of PO. b) FTIR spectra of PO, Gln, the gel supernatant and the aerogel. c) TGA profiles of the OAm-NCs, Gln-NCs and the Gln-NC-based aerogel. 
PO, a soft base, triggers a slow cross-linking of the NCs, which favors the formation of a voluminous gel. On the contrary, when a strong base such as TMAOH was added, a rapid aggregation of the NCs occurred with no gel formation (Figure 5a, Figure S6). Actually, the amount of epoxide controlled the ligand stripping rate and thus the rate of $\mathrm{NC}$ cross-linking, which translated in gels with different voluminosity (Figure 5). In this regard, an excessive amount of PO led to higher NC aggregation and gel shrinkage, while insufficient amounts were not able to crosslink all the particles, resulting in none or partial gelation (Figure 5a).

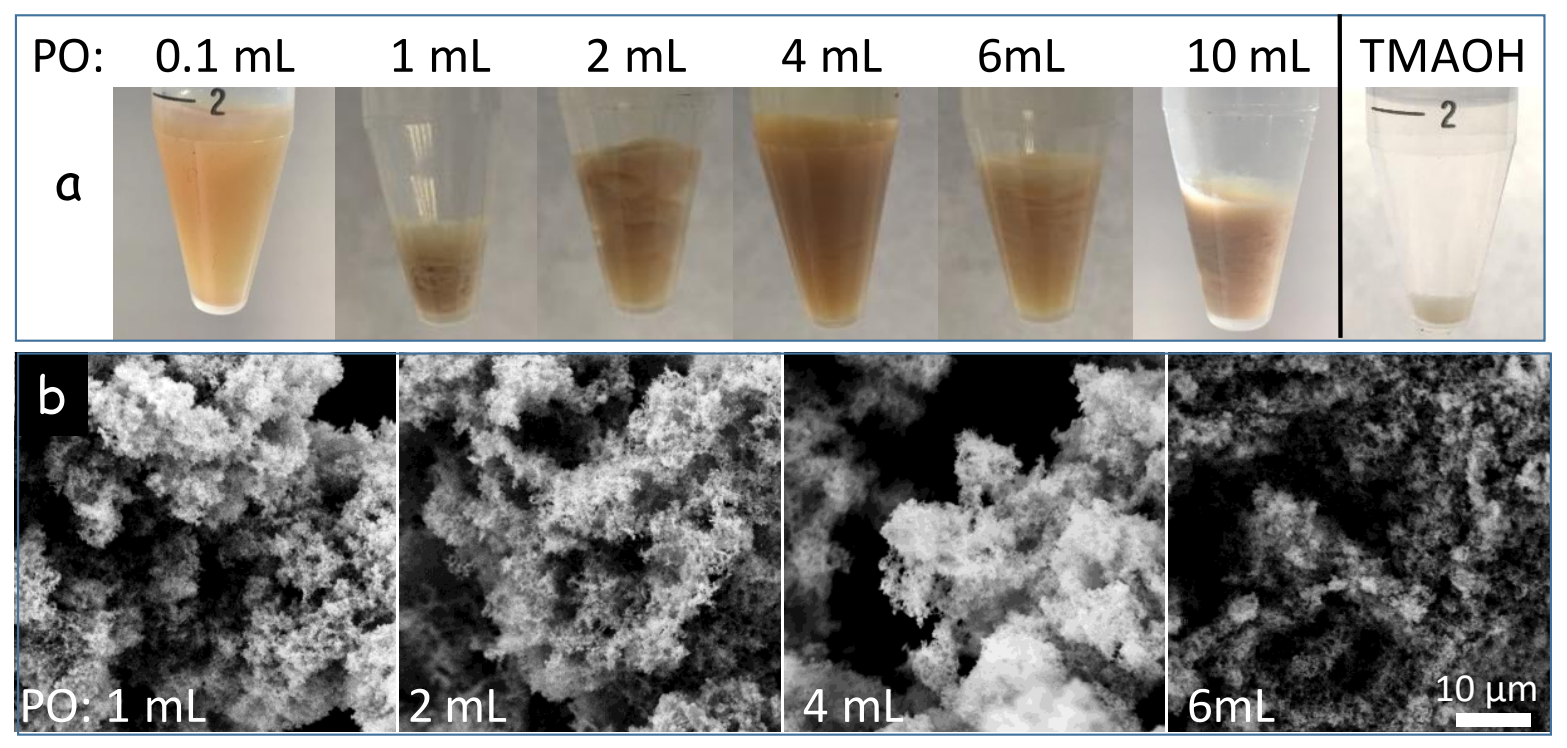

Figure 5. a) Optical photographs of the ceria NC-based gels obtained $24 \mathrm{~h}$ after the introduction of different amounts of PO: $0.1 \mathrm{~mL}$ (no gel formed), $1 \mathrm{~mL}, 2 \mathrm{~mL}, 4 \mathrm{~mL}, 6 \mathrm{~mL}, 8 \mathrm{~mL}$ and $10 \mathrm{~mL}$; or $500 \mu \mathrm{L}$ of $\mathrm{TMAOH}$ (no gel formed, fast $\mathrm{NC}$ aggregation into powder), as indicated on top of each photograph. b) SEM images of the aerogels produced from the gels obtained from $1 \mathrm{~mL}, 2$ $\mathrm{mL}, 4 \mathrm{~mL}$ and $6 \mathrm{~mL}$ of $\mathrm{PO}$.

The use of molecules with multiple epoxy groups had a similar effect as PO. As an example, the addition of NGDE, with 2 epoxy groups instead of PO, also triggered the NC gelation, but with a 
lower voluminosity when added in the same amount as PO. Injection of $11 \mathrm{~mL}(0.057 \mathrm{~mol})$ of NGDE, the molar equivalent to $4 \mathrm{~mL}$ of $\mathrm{PO}$, resulted in gels with dense aggregates of NCs, which we associate to the double number of epoxy groups introduced (Figure 6a). When reducing the amount of NGDE by half, thus introducing the same amount of epoxy groups, less dense aerogels, similar to those produced with PO were obtained (Figure 6b).
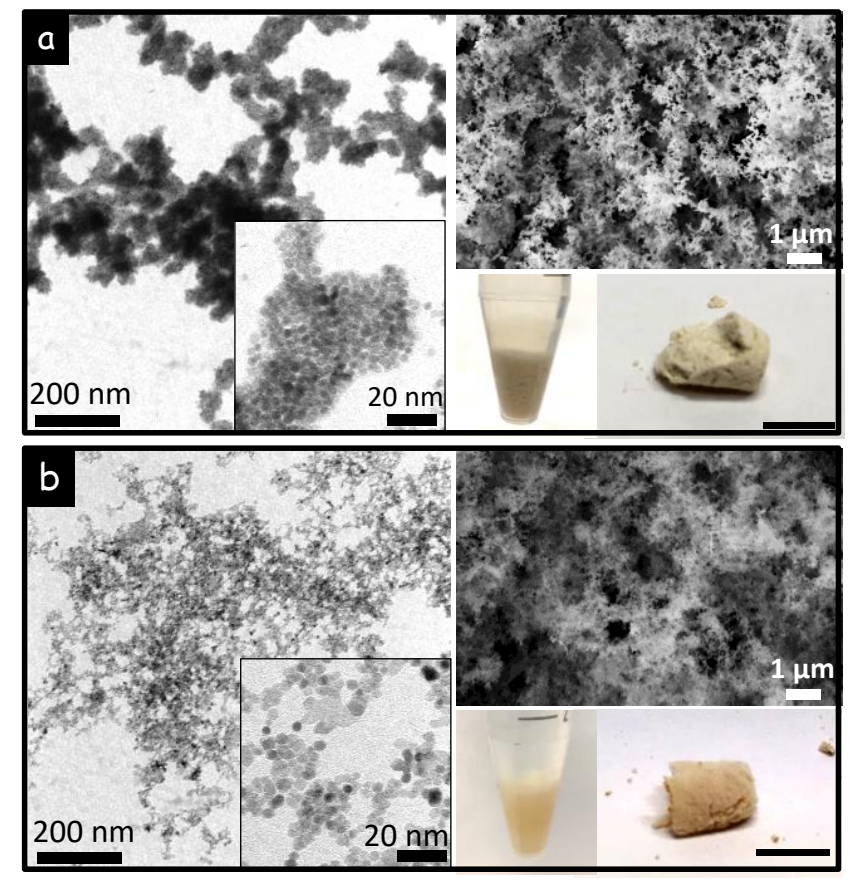

Figure 6. a) TEM, SEM and optical photographs of the ceria NC-based gel and aerogel formed from the addition of $10 \mathrm{~mL}$ of NGDE. b) TEM, SEM and optical photographs of the ceria NCbased gel and aerogel formed from the addition of $5 \mathrm{~mL}$ of NGDE.

While the addition of $\mathrm{H}_{2} \mathrm{O}$ to the MFA resulted in gels with higher voluminosity, the presence of $\mathrm{H}_{2} \mathrm{O}$ was not essential for the $\mathrm{NC}$ gelation to occur. Attempts using MFA as the only solvent also led to NC gelation, but the obtained gels were significantly less voluminous (Figure S3). When replacing MFA $+\mathrm{H}_{2} \mathrm{O}$ with alcohols as the only solvent for $\mathrm{NC}$ gelation, no gel was formed. Upon PO addition to an alcohol solution of NCs, all NCs precipitated. Nevertheless, the addition of small amounts of water to the alcohol also allowed the $\mathrm{NC}$ gelation, although with a moderate 
voluminosity compared with $\mathrm{MFA}+\mathrm{H}_{2} \mathrm{O}$ (Figure S3). Note that the poor miscibility of PO with $\mathrm{H}_{2} \mathrm{O}$ barred the use of $\mathrm{H}_{2} \mathrm{O}$ as the only solvent for NC gelation. Attempts to gelate NCs in the twophase mixture created from the addition of $\mathrm{PO}$ to a $\mathrm{NC}$ solution in water, resulted in $\mathrm{NC}$ precipitation.

The same methodology allowed formation of NC-based ceria gels using ceria NCs functionalized with other amino acids, such as Glu and DA (Figures S4 and S5). However, the gels produced from Glu-NCs and DA-NCs were slightly less voluminous than those produced from Gln-NCs (Figure S5). We hypothesize the different gel voluminosity to be related to variations in the ligand displacement kinetics that would be in part associated to the fact that DA and Glu have just one amino group while Gln has two. Identical amounts of PO may result in a faster ligand displacement in DA- and Glu-NCs than in Gln-NCs and thus in less voluminous gels.

The gelation approach here proposed was also used to produce NC-based ceria aerogels employing NCs with other sizes and geometries, and particularly hyperbranched ceria NCs (Figure 7). ${ }^{35}$ Hyperbranched ceria NCs were characterized by an intrinsic porous structure that provides them with specific surface areas up to $157 \mathrm{~m}^{2} / \mathrm{g} .{ }^{35}$ As for spherical ceria NCs, the surface of ceria hyperbranched NCs was in a first step functionalized with Gln to render the NCs soluble in polar solvents. In a second step, PO was added to trigger gelation. The gel obtained after $24 \mathrm{~h}$ from the injection of PO was dried from supercritical $\mathrm{CO}_{2}$. Figure 7 displays representative TEM and SEM micrographs of the aerogels produced following this procedure. $\mathrm{N}_{2}$ adsorption/desorption isotherm curves of hyperbranched NCs aerogels displayed a type IV character with a H1 hysteresis loop that evidenced mesoporosity (Figure 7c). BET calculations demonstrated large specific surface areas of $200 \mathrm{~m}^{2} / \mathrm{g}$, similar to those measured from aerogels produced from quasi-spherical NCs and above those of the precipitated hyperbranched NCs. 


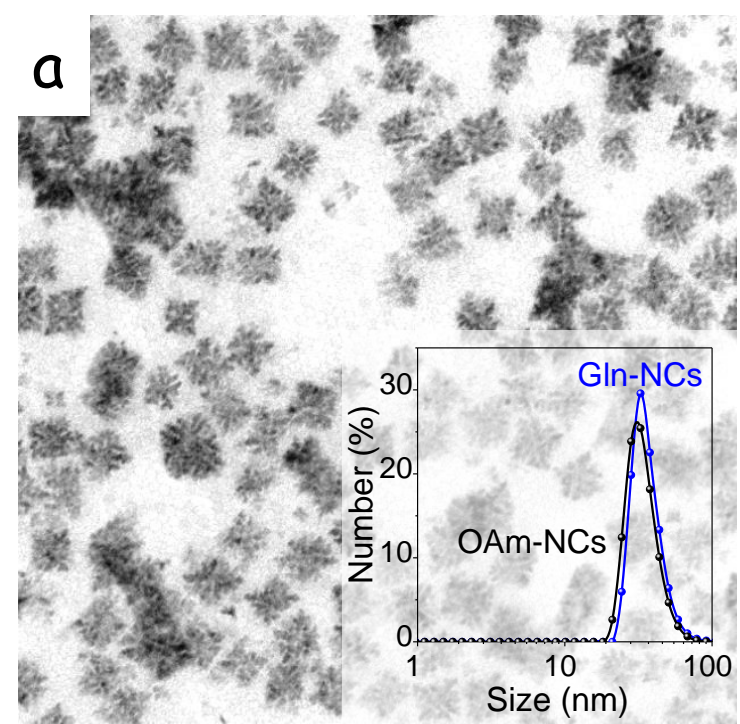

b
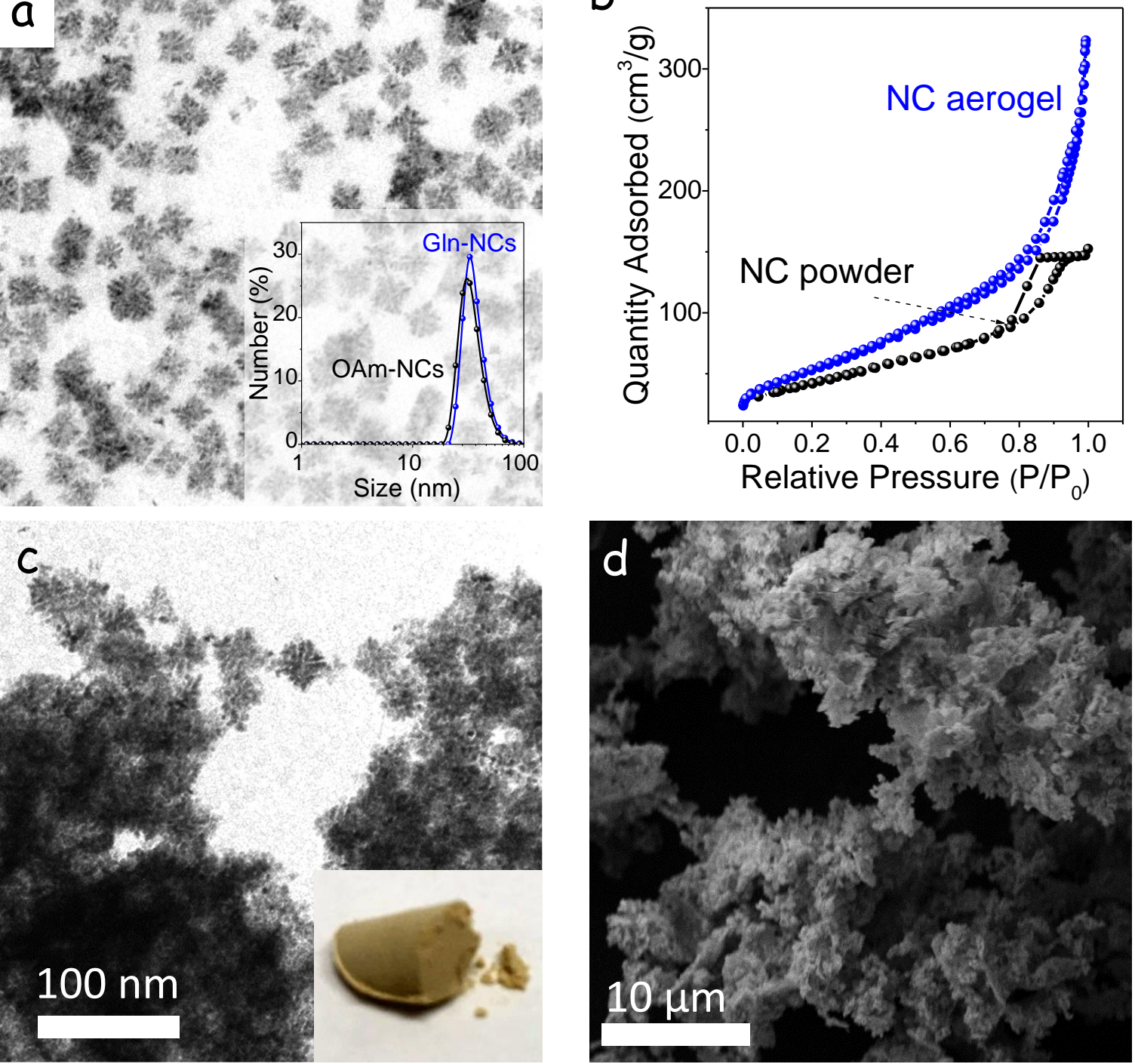

Figure 7. a) TEM micrograph of hyperbranched ceria NCs. The inset displays DLS curves of hyperbranched OAm-NCs and Gln-NCs. b) Adsorption-desorption isotherm obtained from a hyperbranched NC-based ceria aerogel and from a NC powder obtained by precipitation of the colloidal NCs using an antisolvent and posterior centrifugation. Both materials were annealed at 
$400{ }^{\circ} \mathrm{C}$ for $2 \mathrm{~h}$. c) TEM micrograph of the hyperbranched NC-based aerogel and optical photograph of the monolith aerogel (inset). d) SEM micrograph of the hyperbranched NC-based aerogel.

The general approach to produce metal oxide aerogels detailed here was demonstrated for a second oxide besides ceria. As a second example, we targeted the production of NC-based aerogels of titanium dioxide, a key industrial nanomaterial in a range of applications. For this purpose, we produced $\mathrm{TiO}_{2} \mathrm{NCs}$ with controlled geometry and facets. In particular, for the present work, we produced anatase $\mathrm{TiO}_{2}$ nanoplates with ample $\{001\}$ facets following the procedure by Gordon et al. (Figure 8) ${ }^{36}$ Using the same procedure as for ceria NCs, we replaced the native organic ligands from the $\mathrm{TiO}_{2} \mathrm{NC}$ surface by Gln. Subsequently, the addition of $\mathrm{PO}$ to a solution containing $\mathrm{TiO}_{2}$ Gln-NCs resulted in their random aggregation into a network, i.e. its gelation (Figure 8). $\mathrm{TiO}_{2} \mathrm{NCs}$ gelation occurred slightly faster than for $\mathrm{CeO}_{2}$ and it was completed after 60 min of reaction. Super-critical drying of the $\mathrm{NC}$-based $\mathrm{TiO}_{2}$ gels resulted in blue coloured monolithic aerogel (Figure 8d). The blue colour, characteristic of the initial $\mathrm{TiO}_{2} \mathrm{NCs}$, evidenced the presence of a high concentration of oxygen vacancies and the overall nonstoichiometric composition of the $\mathrm{TiO}_{2}$ NCs obtained from the used colloidal synthesis protocol. ${ }^{36}$

Despite the fact that plate-like NCs were prone to stuck together to form compact aggregates, SEM imaging evidenced NC-based $\mathrm{TiO}_{2}$ aerogels to be characterized by highly porous structures. NC-based $\mathrm{TiO}_{2}$ aerogels displayed type IV adsorption/desorption isotherms (Figure 8b) and BET specific surface area up to $70 \mathrm{~m}^{2} / \mathrm{g}$. 

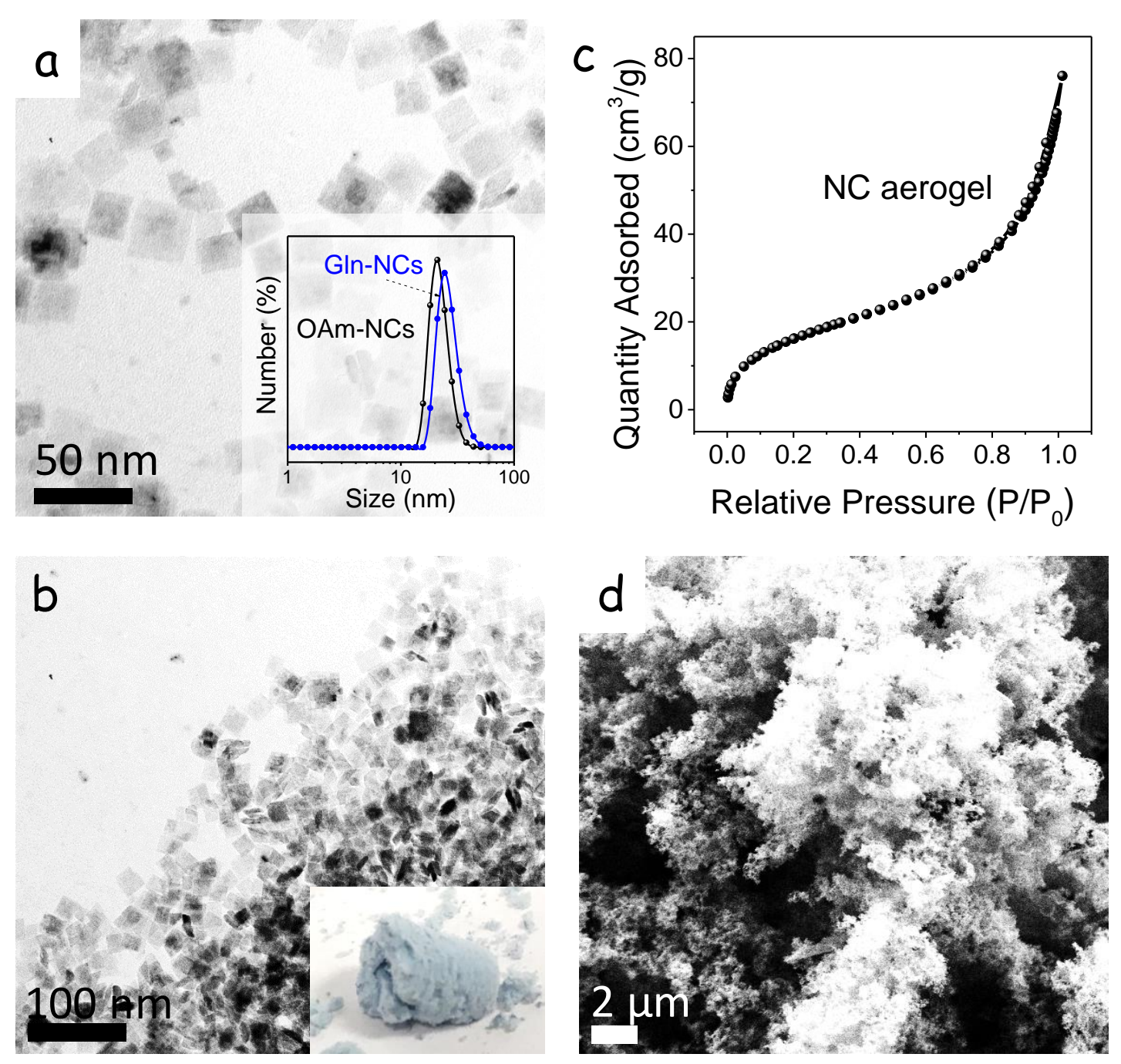

Figure 8. a) TEM micrograph of $\mathrm{TiO}_{2} \mathrm{NCs}$. Inset shows the DLS curves of $\mathrm{TiO}_{2} \mathrm{OAm}-\mathrm{NCs}$ and Gln-NCs. b) Adsorption-desorption isotherms obtained from a NC-based $\mathrm{TiO}_{2}$ aerogel. The material was measured after annealing at $400{ }^{\circ} \mathrm{C}$ for $2 \mathrm{~h}$. c) TEM micrograph of the NC-based $\mathrm{TiO}_{2}$ aerogel and optical photograph of the monolith aerogel (inset). d) SEM micrograph of the NC-based $\mathrm{TiO}_{2}$ aerogel. 


\section{CONCLUSIONS}

A novel strategy to produce crystalline oxide aerogels was detailed. The described approach was based on the cross linking of colloidal NCs by the addition of an epoxide to the colloidal NC dispersion. We hypothesize the epoxide gradually displaced amino acid ligands from the NC surface, thus triggering their slow cross linking into randomly interconnected networks, i.e. their gelation. NC-based ceria aerogels displayed both high surface areas and highly crystalline structures that were associated to the high crystallinity of the precursor NC building blocks. Additionally, the versatility of the proposed strategy was proved by using the same procedure to produce NC-based titanium dioxide aerogels using NC building blocks with controlled geometry and facets.

\section{ASSOCIATED CONTENT}

Supporting Information. The Supporting Information is available free of charge.

Optical photographs of the gelation process; pore size distribution of NC-based aerogel; study of the solvent influence on the gelation process; study of the influence of different amino-acids on the gelation process; study of the NC precipitate after addition of a strong base (PDF)

\section{AUTHOR INFORMATION}

\section{Corresponding Author}

*E-mail: acabot@irec.cat

\section{Author Contributions}

The manuscript was written through contributions of all authors. All authors have given approval to the final version of the manuscript. 


\title{
ACKNOWLEDGMENT
}

This work was supported by the European Regional Development Funds and the Spanish MINECO project SEHTOP (ENE2016-77798-C4-3-R) and TEMPTATION (MAT2016-79455P). TB thanks FI-AGAUR Research Fellowship Program, Generalitat de Catalunya (2015 FI_B 00744). PG acknowledges the People Programme (Marie Curie Actions) of the FP7/2007-2013 European Union Program (TECNIOspring grant agreement no. 600388) and the Agency for Business Competitiveness of the Government of Catalonia, ACCIÓ. SB acknowledges the U.S. National Science Foundation, CHE-1361741.

\author{
ABBREVIATIONS \\ $\mathrm{NC}$, nanocrystal; OAm, oleylamine; ODE, 1-octadecene; $\mathrm{TMOH}$, tetramethylammonium \\ hydroxide pentahydrate; MFA, n-methylformamide; TFA, trifluoroacetic acid; NGDE, neopentyl \\ glycol diglycidyl ether; Gln, L-glutamine; PO, propylene oxide; DA, dopamine hydrochloride; \\ Glu, glutamic acid; TEM, transmission electron microscopy; HRTEM, high-resolution TEM; \\ SEM, scanning electron microscopy; UV-vis, ultraviolet-visible spectroscopy; X-ray power \\ diffraction (XRD); DLS, dynamic light scattering; FTIR, Fourier-transform infrared \\ spectroscopy; TGA, thermogravimetric analysis; BET, Brunauer-Emmet-Teller method; OAm- \\ NC, OAm-capped NCs; Gln-NC, Gln-capped NCs.
}

\section{REFERENCES}

(1) Zhang, J.; Li, C. M. Nanoporous metals: fabrication strategies and advanced electrochemical applications in catalysis, sensing and energy systems. Chem. Soc. Rev. 2012, 41 (21), 7016-7031.

(2) Rolison, D. R. Catalytic Nanoarchitectures--the Importance of Nothing and the Unimportance of Periodicity. Science 2003, 299 (5613), 1698-1701. 
(3) Brinker, C. J.; Scherer, G. W. Hydrolysis and Condensation I: Nonsilicates. in sol-gel science, Academic Press: San Diego, 1990; pp 20-95.

(4) Gash, A. E.; Tillotson, T. M.; Satcher Jr, J. H.; Hrubesh, L. W.; Simpson, R. L. New solgel synthetic route to transition and main-group metal oxide aerogels using inorganic salt precursors. J. Non-Cryst. Solids 2001, 285 (1), 22-28.

(5) Ziegler, C.; Wolf, A.; Liu, W.; Herrmann, A.-K.; Gaponik, N.; Eychmüller, A. Modern Inorganic Aerogels. Angew. Chem. Int. Ed. 2017, 56 (43), 13200-13221.

(6) Katti, A.; Shimpi, N.; Roy, S.; Lu, H.; Fabrizio, E. F.; Dass, A.; Capadona, L. A.; Leventis, N. Chemical, Physical, and Mechanical Characterization of Isocyanate Cross-linked AmineModified Silica Aerogels. Chem. Mater. 2006, 18 (2), 285-296.

(7) Gash, A. E.; Tillotson, T. M.; Satcher, J. H.; Poco, J. F.; Hrubesh, L. W.; Simpson, R. L. Use of Epoxides in the Sol-Gel Synthesis of Porous Iron(III) Oxide Monoliths from Fe(III) Salts. Chem. Mater. 2001, 13 (3), 999-1007.

(8) Laberty-Robert, C.; Long, J. W.; Lucas, E. M.; Pettigrew, K. A.; Stroud, R. M.; Doescher, M. S.; Rolison, D. R. Sol-Gel-Derived Ceria Nanoarchitectures: Synthesis, Characterization, and Electrical Properties. Chem. Mater. 2006, 18 (1), 50-58.

(9) Rechberger, F.; Niederberger, M. Synthesis of aerogels: from molecular routes to 3dimensional nanoparticle assembly. Nanoscale Horizons 2017, 2 (1), 6-30.

(10) Rechberger, F.; Niederberger, M. Translucent nanoparticle-based aerogel monoliths as 3dimensional photocatalysts for the selective photoreduction of $\mathrm{CO}_{2}$ to methanol in a continuous flow reactor. Mater. Horizons 2017, 4 (6), 1115-1121. 
(11) Heiligtag, F. J.; Rossell, M. D.; Suess, M. J.; Niederberger, M. Template-free co-assembly of preformed $\mathrm{Au}$ and $\mathrm{TiO}_{2}$ nanoparticles into multicomponent 3D aerogels. J. Mater. Chem. 2011, 21 (42), 16893-16899.

(12) Heiligtag, F. J.; Kränzlin, N.; Süess, M. J.; Niederberger, M. Anatase-silica composite aerogels: a nanoparticle-based approach. J. Sol-Gel Sci. Technol. 2014, 70 (2), 300-306.

(13) Kovalenko, M. V.; Manna, L.; Cabot, A.; Hens, Z.; Talapin, D. V.; Kagan, C. R.; Klimov, V. I.; Rogach, A. L.; Reiss, P.; Milliron, D. J.; Guyot-Sionnnest, P.; Konstantatos, G.; Parak, W. J.; Hyeon, T.; Korgel, B. A.; Murray, C. B.; Heiss, W. Prospects of Nanoscience with Nanocrystals. ACS Nano 2015, 9 (2), 1012-1057.

(14) Coughlan, C.; Ibáñez, M.; Dobrozhan, O.; Singh, A.; Cabot, A.; Ryan, K. M. Compound Copper Chalcogenide Nanocrystals. Chem. Rev. 2017, 117 (9), 5865-6109.

(15) Sapsford, K. E.; Algar, W. R.; Berti, L.; Gemmill, K. B.; Casey, B. J.; Oh, E.; Stewart, M. H.; Medintz, I. L., Functionalizing Nanoparticles with Biological Molecules: Developing Chemistries that Facilitate Nanotechnology. Chem. Rev. 2013, 113 (3), 1904-2074.

(16) Zhang, C. Carbon dioxide capture: Multiple site absorption. Nat. Energy 2016, 1, 16084.

(17) Ciftja, A. F.; Hartono, A.; Svendsen, H. F. Selection of Amine Amino Acids Salt Systems for $\mathrm{CO}_{2}$ Capture. Energy Procedia 2013, 37, 1597-1604.

(18) Sanz, R.; Calleja, G.; Arencibia, A.; Sanz-Pérez, E. S. $\mathrm{CO}_{2}$ capture with pore-expanded MCM-41 silica modified with amino groups by double functionalization. Microporous and Mesoporous Materials 2015, 209, 165-171.

(19) De Roo, J.; Coucke, S.; Rijckaert, H.; De Keukeleere, K.; Sinnaeve, D.; Hens, Z.; Martins, J. C.; Van Driessche, I. Amino Acid-Based Stabilization of Oxide Nanocrystals in Polar Media: 
From Insight in Ligand Exchange to Solution 1H NMR Probing of Short-Chained Adsorbates. Langmuir 2016, 32 (8), 1962-1970.

(20) Sousa, M. H.; Rubim, J. C.; Sobrinho, P. G.; Tourinho, F. A. Biocompatible magnetic fluid precursors based on aspartic and glutamic acid modified maghemite nanostructures. J. Magn. Magn. Mater. 2001, 225 (1), 67-72.

(21) Shultz, M. D.; Reveles, J. U.; Khanna, S. N.; Carpenter, E. E. Reactive Nature of Dopamine as a Surface Functionalization Agent in Iron Oxide Nanoparticles. J. Am. Chem. Soc. 2007, 129 (9), 2482-2487.

(22) Stamplecoskie, K. G.; Kamat, P. V. Size-Dependent Excited State Behavior of Glutathione-Capped Gold Clusters and Their Light-Harvesting Capacity. J. Am. Chem. Soc. 2014, $136(31), 11093-11099$.

(23) Alessandro, T. Catalysis by ceria and related materials. World Scientific: 2002, Vol. 2.

(24) Bell, A. T., The Impact of Nanoscience on Heterogeneous Catalysis. Science 2003, 299 (5613), 1688-1691.

(25) Xu, H.; Wang, A.-L.; Tong, Y.-X.; Li, G.-R., Enhanced catalytic activity and stability of $\mathrm{Pt} / \mathrm{CeO}_{2} / \mathrm{PANI}$ hybrid hollow nanorod arrays for methanol electro-oxidation. ACS Catalysis 2016, $6(8), 5198-5206$.

(26) Zhou, H.-P.; Wu, H.-S.; Shen, J.; Yin, A.-X.; Sun, L.-D.; Yan, C.-H., Thermally Stable Pt/CeO2 Hetero-Nanocomposites with High Catalytic Activity. J. Am. Chem. Soc. 2010, 132 (14), 4998-4999.

(27) Wang, D.; Kang, Y.; Doan-Nguyen, V.; Chen, J.; Küngas, R.; Wieder, N. L.; Bakhmutsky, K.; Gorte, R. J.; Murray, C. B., Synthesis and Oxygen Storage Capacity of Two-Dimensional Ceria Nanocrystals. Angew. Chem. Int. Ed. 2011, 50 (19), 4378-4381. 
(28) Zhou, L.; Li, X.; Yao, Z.; Chen, Z.; Hong, M.; Zhu, R.; Liang, Y.; Zhao, J., TransitionMetal Doped Ceria Microspheres with Nanoporous Structures for CO Oxidation. Sci. Rep. 2016, $6,23900$.

(29) Kharton, V. V.; Figueiredo, F. M.; Navarro, L.; Naumovich, E. N.; Kovalevsky, A. V.; Yaremchenko, A. A.; Viskup, A. P.; Carneiro, A.; Marques, F. M. B.; Frade, J. R., Ceria-based materials for solid oxide fuel cells. J. Mater. Sci. 2001, 36 (5), 1105-1117.

(30) Liao, L.; Mai, H. X.; Yuan, Q.; Lu, H. B.; Li, J. C.; Liu, C.; Yan, C. H.; Shen, Z. X.; Yu, T., Single $\mathrm{CeO}_{2}$ Nanowire Gas Sensor Supported with Pt Nanocrystals: Gas Sensitivity, Surface Bond States, and Chemical Mechanism. J. Phys. Chem. C 2008, 112 (24), 9061-9065.

(31) Channei, D.; Inceesungvorn, B.; Wetchakun, N.; Ukritnukun, S.; Nattestad, A.; Chen, J.; Phanichphant, S., Photocatalytic degradation of methyl orange by $\mathrm{CeO}_{2}$ and $\mathrm{Fe}-$ doped $\mathrm{CeO}_{2}$ films under visible light irradiation. Sci. rep. 2014, 4, 5757.

(32) Kwon, H. J.; Cha, M.-Y.; Kim, D.; Kim, D. K.; Soh, M.; Shin, K.; Hyeon, T.; Mook-Jung, I., Mitochondria-Targeting Ceria Nanoparticles as Antioxidants for Alzheimer's Disease. ACS Nano 2016, 10 (2), 2860-2870.

(33) Fujishima, A.; Rao, T. N.; Tryk, D. A., Titanium dioxide photocatalysis. J. Photochem. Photobiol C: Photochemistry Reviews 2000, 1 (1), 1-21.

(34) Zhao, Z.; Tian, J.; Sang, Y.; Cabot, A.; Liu, H., Structure, synthesis, and applications of $\mathrm{TiO}_{2}$ nanobelts. Adv. Mater. 2015, 27 (16), 2557-2582.

(35) Berestok, T.; Guardia, P.; Blanco, J.; Nafria, R.; Torruella, P.; López-Conesa, L.; Estradé, S.; Ibáñez, M.; de Roo, J.; Luo, Z.; Cadavid, D.; Martins, J. C.; Kovalenko, M. V.; Peiró, F.; Cabot, A., Tuning Branching in Ceria Nanocrystals. Chem. Mater. 2017, 29 (10), 4418-4424. 
(36) Gordon, T. R.; Cargnello, M.; Paik, T.; Mangolini, F.; Weber, R. T.; Fornasiero, P.; Murray, C. B., Nonaqueous Synthesis of $\mathrm{TiO}_{2}$ Nanocrystals Using $\mathrm{TiF}_{4}$ to Engineer Morphology, Oxygen Vacancy Concentration, and Photocatalytic Activity. J. Am. Chem. Soc. 2012, 134 (15), 6751-6761.

(37) Kakiuchi, H.; Iijima, T., The ring-opening reactions of propylene oxide with chloroacetic acids. Tetrahedron 1980, $36(8), 1011-1016$.

TOC graphic
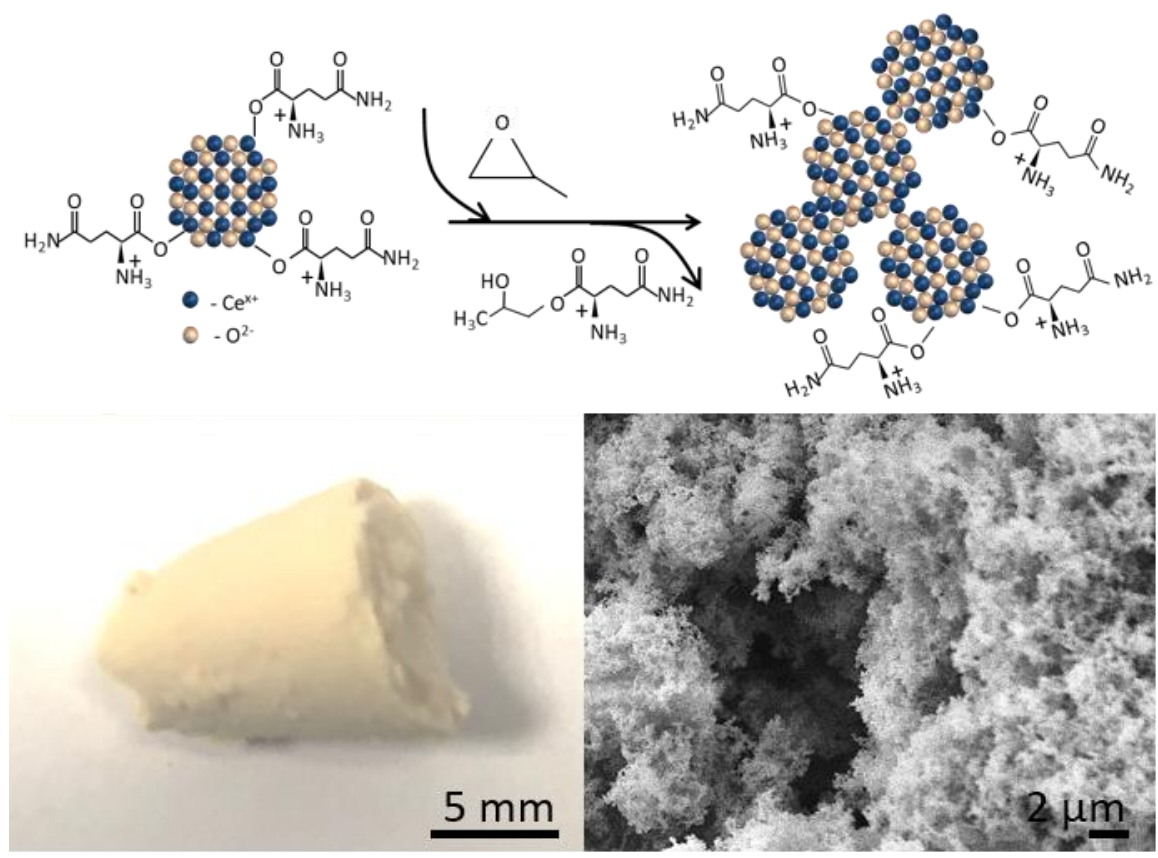